\title{
Loss in Axial Compressor Bleed Systems
}

\author{
S.D. Grimshaw, J. Brind, G. Pullan \\ Whittle Laboratory \\ Department of Engineering \\ University of Cambridge \\ Cambridge, CB3 ODY, UK \\ Email:sdg33@cam.ac.uk
}

\section{R. Seki}

\author{
Fluid Dynamics Research Department \\ Research \& Innovation Center \\ Mitsubishi Heavy Industries, Ltd. \\ 2-1-1 Shinhama Arai-Cho Takasago \\ Hyogo, Japan
}

\begin{abstract}
Loss in axial compressor bleed systems is quantified, and the loss mechanisms identified, in order to determine how efficiency can be improved. For a given bleed air pressure requirement, reducing bleed system loss allows air to be bled from further upstream in the compressor, with benefits for the thermodynamic cycle. A definition of isentropic efficiency which includes bleed flow is used to account for this. Two cases with similar bleed systems are studied: a low-speed, single-stage research compressor and a large industrial gas turbine high-pressure compressor.

A new method for characterising bleed system loss is introduced, using research compressor test results as a demonstration case. A loss coefficient is defined for a control volume including only flow passing through the bleed system. The coefficient takes a measured value of $95 \%$ bleed system inlet dynamic head, and is shown to be a weak function of compressor operating point and bleed rate, varying by $\pm 2.2 \%$ over all tested conditions. This loss coefficient is the correct non-dimensional metric for quantifying and comparing bleed system performance.

Computations of the research compressor and industrial gas turbine compressor identify the loss mechanisms in the bleed system flow. In both cases, approximately two-thirds of total loss is due to shearing of a high-velocity jet at the rear face of the bleed slot, one quarter is due to mixing in the plenum chamber and the remainder occurs in the off-take duct. Therefore, the main objective of a designer should be to diffuse the flow within the bleed slot. A redesigned bleed slot geometry is presented that achieves this objective and reduces the loss coefficient by $31 \%$.
\end{abstract}




\section{INTRODUCTION}

The aims of this paper are to determine how bleed system losses should be quantified and to show how bleed system losses are generated. This knowledge is a step towards the design of improved secondary air systems with a reduced thermodynamic cycle efficiency penalty. Our approach is to consider a control volume which includes only flow passing through the bleed system and to split the flow field into four zones, as shown in Fig. 1, so that individual loss mechanisms can be identified. Relevant literature is now summarised in order to develop a context for the contributions of the present work.
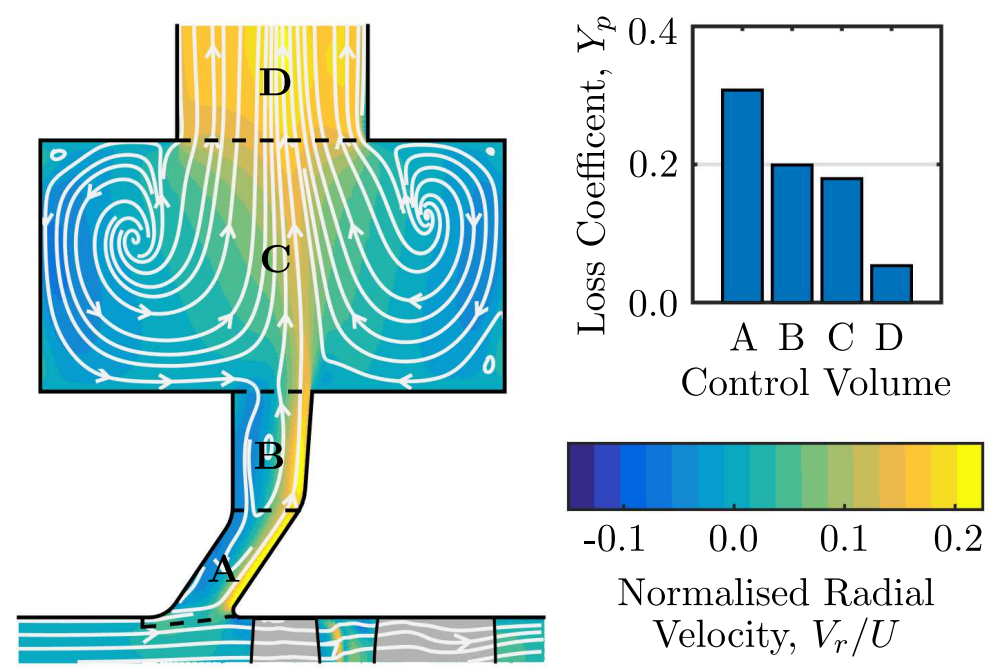

Fig. 1: Bleed system flow field and loss breakdown.

\section{Axial compressor bleed}

In aero-engines and land-based gas turbines, 'bleed flow' is removed part-way through the compressor for use in combustor and turbine cooling, pressurising cavities, cabin air, and for stage matching of the compressor during off-design operation. The fraction of air removed from the mainstream, the bleed rate, $f_{\mathrm{b}}$, can be as much as $20 \%$ when used for stage matching at start up or cooling in high-temperature military engines [1]. However, in this paper the bleed rate varies from $0 \%$ to $6.2 \%$, values representative of design operating conditions in an industrial gas turbine. The term 'bleed system' is used to describe the group of components shown in Fig. 2, these are: an axisymmetric slot or set of holes in the compressor casing through which air is extracted from the mainstream, an annular plenum chamber, and off-take ducts through which bleed air in the plenum chamber is ducted to the secondary air system.

\section{Bleed and cycle efficiency}

Reducing loss through the bleed system can increase cycle efficiency [2]. For a given bleed air pressure requirement, reducing stagnation pressure loss in the bleed system allows air to be bled from a compressor stage further upstream (lower pressure). This means that less work is done on fluid extracted from the main annulus flow and cycle efficiency increases. As an example, the improvement in efficiency is estimated for a representative large industrial gas turbine with a pressure ratio of 18 and a turbine-entry to compressor-entry temperature ratio of 5.5. The compressor stagnation temperature rise is split evenly across 16 stages. Bleed extraction of $4 \%$ local mainstream flow rate is taken after stages 6,10 , and 13 . The working 
fluid is taken as a perfect gas with constant properties, the combustor is modelled as a constant-pressure heater, and all turbomachinery has a polytropic efficiency of 0.9. Moving each bleed one stage upstream (so they are positioned after stages 5,9 , and 12 ) reduces the compressor specific work input by $0.8 \%$. This modification does not affect the combustor heat input or the turbine work output and the cycle efficiency improvement is $0.43 \%$ points. A secondary benefit, not accounted for in the analysis, is that bleeding at a lower temperature reduces coolant flow requirements.

\section{Bleed system loss}

The effect of bleed slot geometry on pressure recovery was studied by Leishman et al. [2,3] using a cascade rig. Pressure recovery is defined as $\left(p_{\mathrm{S}}-p_{\mathrm{S} 1}\right) /\left(p_{01}-p_{\mathrm{S} 1}\right)$, where $p_{\mathrm{S}}$ is the plenum static pressure, $p_{\mathrm{S} 1}$ is the cascade inlet free-stream static pressure, and $\left(p_{01}-p_{\mathrm{S} 1}\right)$ is the cascade inlet dynamic head. It was found that increasing the radius between the casing and the front face of the bleed slot from 0 to $58 \%$ of the slot axial length improves pressure recovery by 0.21 cascade inlet dynamic heads.

Peltier et al. $[4,5]$ have used experiments and computations to study different bleed system configurations. Here, a static pressure ratio $p_{2} / p_{\mathrm{b}}$ is used to characterise bleed performance where $p_{\mathrm{b}}$ is static pressure in an off-take duct and $p_{2}$ is static pressure on the casing of the mainstream flow, downstream of the bleed slot. These measurements show that at $9 \%$ bleed an optimised design with a $45^{\circ}$ slot, downstream lip and increased diffusion between slot and plenum chamber, has a pressure ratio of 1.004 compared to the datum design with a simple $90^{\circ}$ slot, which has a pressure ratio of 1.105 .

Bleed system loss was investigated using an annular cascade fitted with a bleed slot, plenum chamber and off-take ducts by Gomes et al. [6]. A bleed loss coefficient is defined as $\left(p_{01}-p_{0 \mathrm{~b}}\right) /\left(p_{01}-p_{1}\right)$, where $p_{01}$ and $\left(p_{01}-p_{1}\right)$ are the average stagnation pressure and dynamic head across the passage upstream of the bleed slot, and $p_{0 \mathrm{~b}}$ is the average stagnation pressure in the off-take duct. Measurements show that loss in stagnation pressure, for bleed rates from $0 \%$ to $15 \%$, is between 1 and 1.5 dynamic heads of the mainstream flow.

Walker et al. studied the use of bleed slots to reduce combustor diffuser length [7] and in the design of aggressive compressor S-ducts [8]. In both cases, bleed is used to prevent boundary layer separation on highly loaded end walls. For the diffuser, a bleed loss coefficient is defined similar to that used by Gomes et al. [6]. For the S-duct, a bleed loss coefficient is not reported. However, the duct loss is calculated using a control volume which is defined so as to exclude bleed air.

Each of the studies described above uses a distinct parameter for bleed system performance, making it difficult to compare different experiments and designs. Also, for more realistic cases where turbomachinery is present in the main annulus, the parameters defined above are not comparable between different compressor operating points, as the main stream dynamic head varies.

\section{Contributions and layout of the paper}

This paper introduces a loss coefficient based on a control volume which includes only the flow passing through the bleed system. Non-dimensional entropy generation rate, also employing the bleed system control volume, is obtained from computational fluid dynamics (CFD) simulations and is used to identify the sources of loss in the bleed system flow. These parameters are the appropriate non-dimensional figures of merit to assess bleed system performance and identify loss gener- 
ation.

The paper is organised into five sections. The first section describes the two cases studied and the experimental and numerical methods employed. In the second section, bleed system loss is quantified using experimental results from a research compressor. In the third section, CFD results for the research compressor are used to examine the flow field, identifying loss mechanisms and the contributions of these to total loss. In the fourth section, CFD simulations of an industrial gas turbine compressor bleed system are analysed and compared with the research compressor results. Finally, the implications of this work for the design of compressor bleed systems are discussed.

\section{EXPERIMENTAL AND COMPUTATIONAL METHODS}

Two cases are studied: a full-scale industrial gas turbine high-pressure compressor and a single-stage research compressor. Both include a bleed system consisting of an axisymmetric bleed slot, annular plenum chamber and four off-take ducts. The research compressor is designed to be a low-speed representation of the industrial gas turbine; the casing radius is $30 \%$ of full scale, the Reynolds number based on mainstream conditions and bleed slot length is approximately one order of magnitude lower than full scale, and the non-dimensional blade speed is $40 \%$ of full scale.

Figure 2 shows meridional cross sections of the bleed systems for the two cases. Bleed system geometry is similar in both as the bleed slot comes from the same 'family' of designs, however, there are differences in the geometric details: The downstream inlet radius, $R_{\mathrm{dn}}$, is greater for the industrial gas turbine, and the upstream inlet radius, $R_{\mathrm{up}}$, is greater for the research compressor. In the research compressor, the off-take duct centreline is at the same axial position as the bleed slot exit. In the full scale machine the off-take is offset forwards by $60 \%$ duct diameter from the bleed slot. The research compressor off-take ducts are equally spaced by $90^{\circ}$ around the circumference of the machine, while the full-scale machine off-takes are arranged in pairs on opposite sides of the annulus.

In this paper, experimental results are presented for the research compressor, and CFD simulations are analysed and compared for the research compressor and industrial gas turbine. The remainder of this section describes the methods used to obtain these results.

\section{Research compressor experiments}

Table 1 provides data for the research compressor experimental rig and Fig. 3 shows the layout of the rig and position of measurement stations.

Bleed air is extracted using vacuum pumps attached to the off-take ducts with the bleed rate set by control valves and measured with orifice plates. The stagnation pressure of the bleed flow is measured 1.75 duct diameters into the off-take by pneumatically averaging the pressure recorded by a rake of five Pitot tubes. Tappings are used to measure the static pressure distribution on the front face of the bleed slot; the tapping locations are shown in Fig. 2(a). Five-hole probe area traverses are performed at the stations shown in Fig. 3 with an automated traversing system. Traverse grids consist of 21 evenly spaced pitchwise points and 21 radial points clustered towards the endwalls.

Air density at inlet is calculated from measurements of atmospheric pressure using a digital barometer and temperature at rig inlet using thermocouples. The rig inlet mass flow is obtained from a calibrated intake, and averaged stagnation 


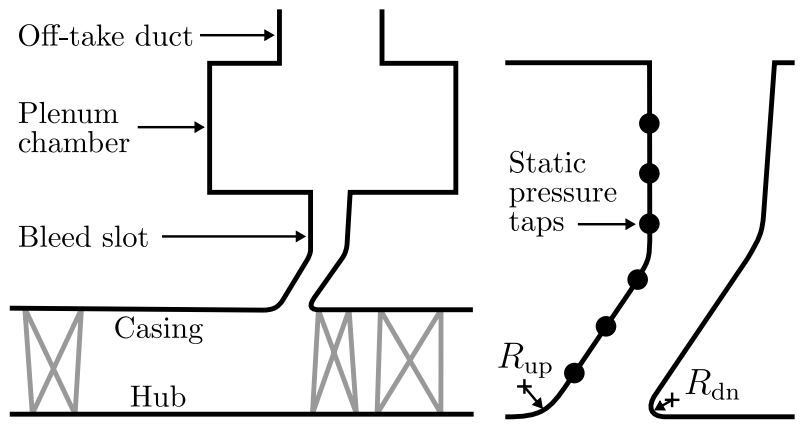

(a) Research compressor

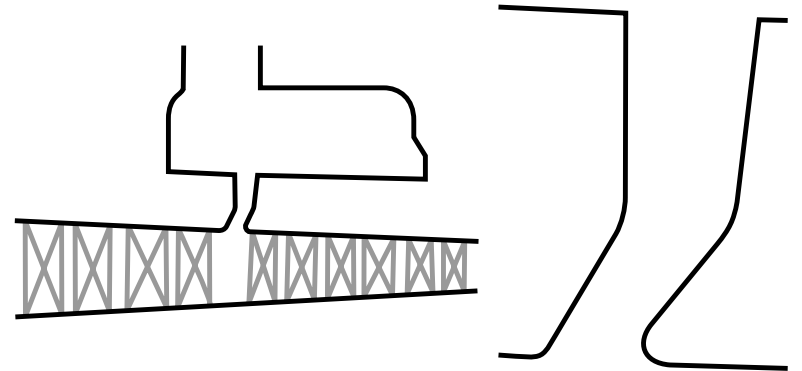

(b) Industrial gas turbine compressor

Fig. 2: Meridional cross sections of (a) research compressor and (b) industrial gas turbine bleed systems. For the research compressor, slot static pressure tappings are marked with dots.

\begin{tabular}{lc}
\hline Hub-to-tip radius ratio & 0.75 \\
Design $\phi=V_{x} / U$ & 0.43 \\
Design $\psi=\left(p_{2}-p_{01}\right) /\left(\frac{1}{2} \rho U^{2}\right)$ & 0.48 \\
Rotor tip gap & $1.7 \% c_{x}$ \\
Rotor $R e=\left(\rho V_{1}^{\text {rel }} c\right) / \mu$ & $1.6 \times 10^{5}$ \\
Rotor blade count & 58 \\
IGV and Stator blade count & 60 \\
Tip speed Mach number & 0.23 \\
\hline
\end{tabular}

Table 1: Data for low-speed research compressor rig.

pressures at each of the stations are also found from calibrations (full details of the calibrations are given in the Appendix). The stage inlet flow coefficient (i.e. at station 3) is obtained by subtracting the measured bleed mass flow rate from the rig inlet mass flow rate. The reaction torque on the motor is measured using a lever arm and load cell and this, along with shaft speed, is used to calculate compressor power output.

\section{Numerical method}

CFD simulations are used to obtain information on the bleed system flow field where measurements do not exist, both for the research compressor and the full-scale industrial gas turbine compressor. All calculations were performed using 
Measurement stations:

(1) Rig inlet

(2) Upstream of slot

(3) Stage inlet

(4) Downstream of rotor

(5) Downstream of stator

(1)

(2) (3)

(4)

(5)

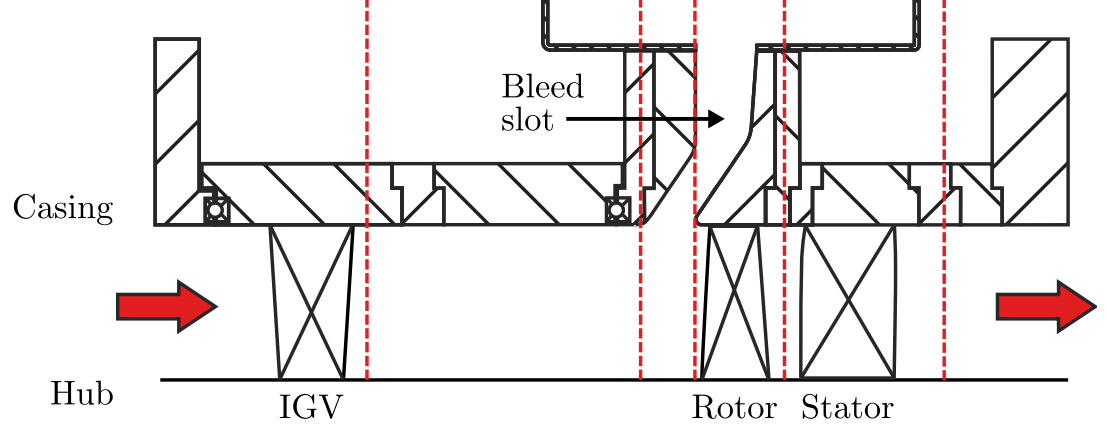

Fig. 3: Meridional view of research compressor and bleed system showing measurement planes.

TURBOSTREAM, a structured multi-block Reynolds-Averaged Navier-Stokes (RANS) code [9]. A second-order accurate finite-volume discretisation method is applied, with single-step explicit time marching and multigrid. The Spalart-Allmaras turbulence model is used, with adaptive wall functions and fully-turbulent boundary layers.

\section{Research compressor computational model}

The research compressor computational domain includes the compressor mainstream and bleed flow paths, shown in Fig. 2(a), extending from upstream of the IGVs to downstream of the stator and also into the bleed off-take duct. The experiment is set up with four equally spaced off-take ducts so a periodic quarter-annulus sector is modelled to capture the circumferentially non-uniform flow in the plenum. The computational mesh was generated using the commercial software NUMECA AUTOGRID5. 'O' blocks are used to grid the blade surfaces, rotor tip gap and off-take duct, with 'H' blocks used elsewhere. In the main passage, there are 121 spanwise points with 21 points in the rotor tip gap. In the bleed slot, there are 45 points across the slot and 139 radial points. The mesh has approximately 75 million nodes in total. The non-dimensional wall cell size $\Delta y^{+}$is less than 8 on the blade surfaces, and less than 4 in the bleed slot. The calculation is run 'frozen rotor', i.e. a time-steady simulation of the quarter-annulus mesh where the blades are stationary.

Radial profiles of stagnation pressure, temperature and flow angle are imposed upstream of the IGVs based on experimental measurements. An outlet mass flow boundary condition is applied in the off-take duct to give the correct flow rate through the bleed system. A downstream contraction in the main annulus with a fixed exit static pressure sets the compressor operating point. The simulation was performed for the design stage inlet flow coefficient $\phi_{\text {stg }}=0.43$ and bleed rate $f_{b}=4.1 \%$.

\section{Industrial gas turbine computational model}

The computational domain for the industrial gas turbine case includes the high pressure compressor and bleed system as shown in Fig. 2(b). This includes five stages with the bleed slot located between the second and third stages. The bleed system, second stator row and third rotor row are modelled with a half-annulus periodic sector, since the off-take ducts are not evenly spaced and only have one plane of symmetry. The other upstream and downstream rows are simulated as single 
passages with mixing plane interfaces.

The computational mesh is generated using in-house Mitsubishi Heavy Industries (MHI) software. ' $\mathrm{H}$ ' blocks are used throughout and the slot is spanned by 49 axial points and 92 radial points. The entire domain has approximately 129 million nodes. The simulation is run frozen rotor at the design operating point and with bleed rate $f_{\mathrm{b}}=3.9 \%$.

\section{QUANTIFICATION OF BLEED SYSTEM LOSS}

This section introduces a method for quantifying bleed system loss using the research compressor test results as a demonstration case. First, measurements of annulus-averaged isentropic efficiency characteristics are presented. Second, a bleed system loss coefficient is defined and measurements of this new parameter are presented.

\section{Isentropic efficiency}

The power supplied to fluid passing through the compressor can be found by applying the steady flow energy equation,

$$
-\dot{W}_{x}=\dot{m}_{\mathrm{b}} h_{0 \mathrm{~b}}+\left(\dot{m}_{1}-\dot{m}_{\mathrm{b}}\right) h_{05}-\dot{m}_{1} h_{01}
$$

where stations 1 and 5 are shown in Fig. 3, and subscript b denotes conditions in the bleed system off-take ducts. For an isentropic process in incompressible flow, $\Delta h_{0}=\Delta p_{0} / \rho$. The actual power input to the compressor is found from a measured torque $\tau$ and angular velocity $\omega$. An isentropic efficiency for a rig control volume (station 1 to 5 plus bleed system) can then be defined,

$$
\eta_{\text {rig }}=\frac{\dot{W}_{x, s}}{\dot{W}_{x}}=\frac{\dot{m}_{\mathrm{b}} p_{0 \mathrm{~b}} / \rho+\left(\dot{m}_{1}-\dot{m}_{\mathrm{b}}\right) p_{05} / \rho-\dot{m}_{1} p_{01} / \rho}{\tau \omega} .
$$

This formulation of isentropic efficiency accounts for lost work in the mainstream and bleed flow paths. A similar analysis for a control volume including only the compressor stage downstream of the bleed slot (stations 3 to 5) yields,

$$
\eta_{\mathrm{stg}}=\frac{\left(\dot{m}_{1}-\dot{m}_{\mathrm{b}}\right)\left(p_{03}-p_{05}\right) / \rho}{\tau \omega}
$$

where station 3 is downstream of the bleed slot and upstream of the rotor (Fig. 3). This formulation of isentropic efficiency accounts for lost work in the compressor stage only.

Figure 4 shows measured rig efficiency characteristics, Eq. (2), for bleed rates $f_{\mathrm{b}}=0 \%$ to $f_{\mathrm{b}}=6.2 \%$. The peak efficiency drops by $2.0 \%$ points as the bleed rate is increased from zero to $6.2 \%$. The characteristics also shift to higher flow coefficients with increasing bleed rate. This is because increased bleed reduces the mass flow rate downstream of the slot, so the compressor stage takes a different operating point at the same rig inlet flow coefficient.

Figure 5 shows measured stage efficiency characteristics, Eq. (3), at different bleed rates. The stage efficiency is plotted against stage inlet flow coefficient to remove the effect of bleed rate on stage mass flow. Characteristics for the different bleed rates collapse towards a single curve, with small variations in the peak stage efficiency of $\pm 0.2 \%$ points. To a close approximation the stage operates on its normal, zero-bleed efficiency characteristic in cases with bleed. At the bleed rates tested, bleed extraction causes a negligible spanwise redistribution of the flow such that the annulus-averaged performance characteristics of the downstream stage are not affected. 


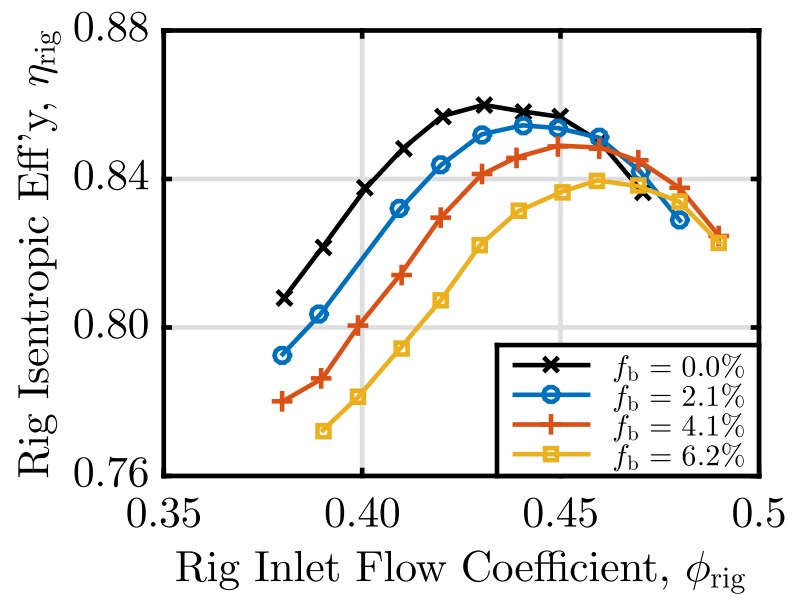

Fig. 4: Measured isentropic efficiency characteristics for rig control volume at different bleed rates. The characteristics shift downwards and to the right as bleed rate is increased.

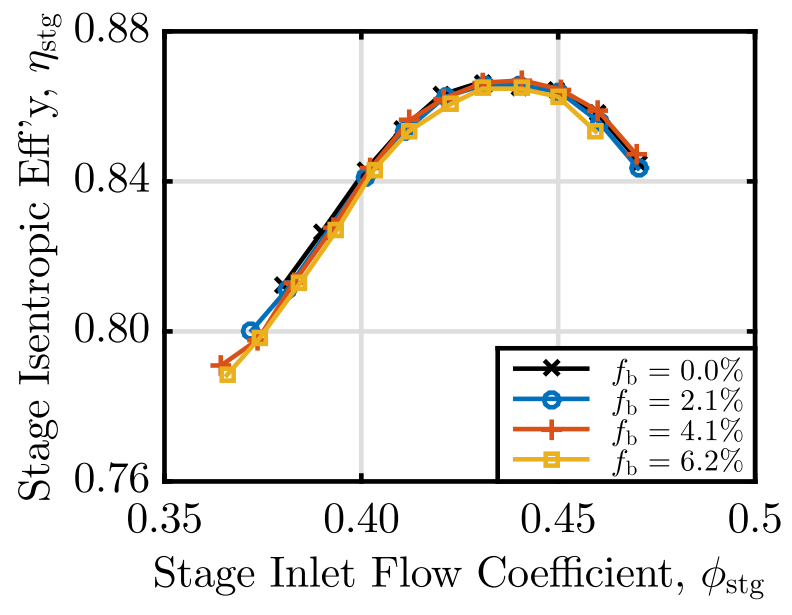

Fig. 5: Measured isentropic efficiency characteristics for stage control volume at different bleed rates. The characteristics collapse towards a single curve.

Collapse of the stage efficiency curves for different bleed rates shows that the drop in peak rig efficiency is not due to increased loss in the mainstream. In order to separate the loss in the bleed flow from the mainstream flow, a control volume is defined as shown in Fig. 6. The control volume inlet is at station 2 upstream of the bleed slot and its lower boundary is defined by a stagnation streamsurface which separates the mainstream flow passing through the downstream stage from the bleed flow. The lost efficiency caused by the bleed system loss is given by,

$$
\Delta \eta=\frac{\dot{m}_{\mathrm{b}}\left(p_{0 \mathrm{CVin}}-p_{0 \mathrm{~b}}\right) / \rho}{\tau \omega}
$$

where subscript 'CVin' denotes the conditions at inlet to the control volume shown in Fig. 6. $p_{0 \text { CVin }}$ is calculated from inlet Pitot and static measurements using a calibration factor as described in the Appendix. The calibration is derived using traverse data at station 2 above the height of the stagnation streamsurface. The spanwise position of the streamsurface is found by integrating the traverse measurements down from the casing until the mass flow of the bleed is obtained. 


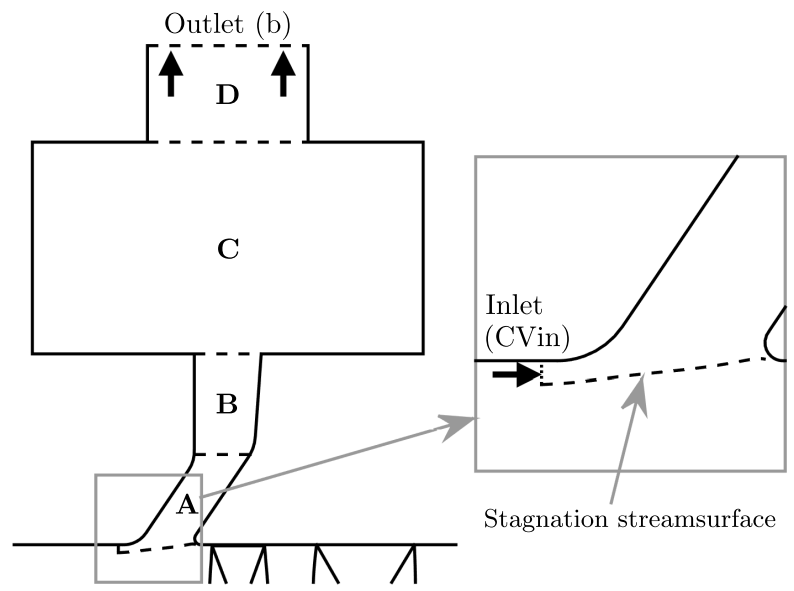

Fig. 6: Control volume for bleed system flow, showing stagnation streamsurface and sub-volumes A to D.

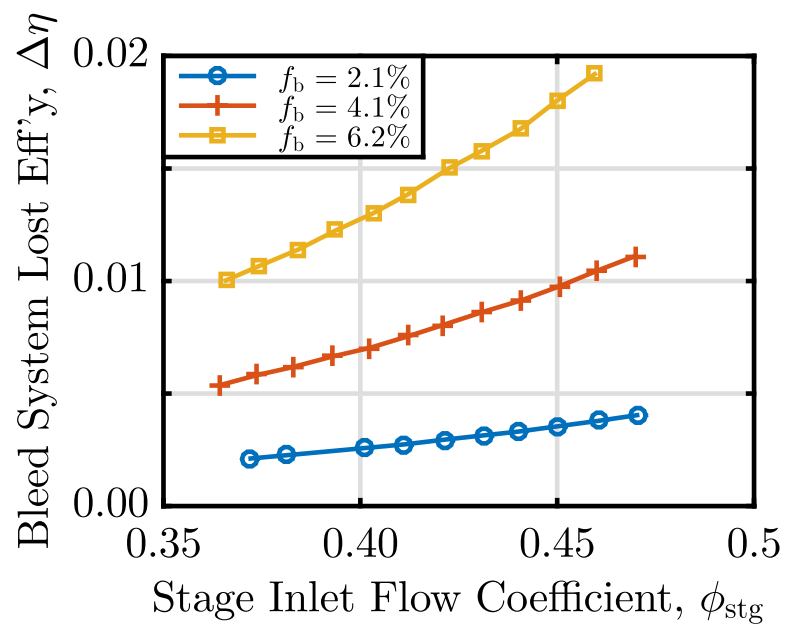

Fig. 7: Measured bleed system lost efficiency characteristics at different bleed rates. The bleed system lost efficiency increases with bleed rate and flow coefficient.

Figure 7 shows the bleed system lost efficiency, Eq. (4), plotted against rig inlet flow coefficient for varying bleed rate. For a fixed rig inlet flow coefficient, the lost efficiency increases with increased bleed rate because the mass flow through the bleed system increases. Also, for a fixed percentage bleed rate, the lost efficiency decreases as the compressor is throttled because the bleed mass flow reduces.

\section{Stagnation pressure loss coefficient}

The bleed system lost efficiency, Fig. 7, is a function of both compressor operating point and bleed rate. Comparisons between different bleed systems are only valid when both are matched, so a metric which removes this dependence is required. A stagnation pressure loss coefficient for the flow passing through the bleed system control volume can be defined,

$$
Y_{p}=\frac{p_{0 \mathrm{CVin}}-p_{0 \mathrm{~b}}}{\left(p_{0}-p\right)_{\mathrm{CVin}}},
$$

where $\left(p_{0}-p\right)_{\mathrm{CVin}}$ is the mass-averaged dynamic head at inlet to the control volume, calculated from inlet Pitot and static measurements with a calibration factor as described in the Appendix. This is the appropriate non-dimensional parameter for bleed system performance, but it has not been previously reported in the literature. Using mainstream conditions (station 2) 
as the reference instead of the control volume inlet conditions (station CVin) would produce a loss coefficient dependent on the compressor operating point because the mainstream dynamic head can change without any associated change in bleed system performance.

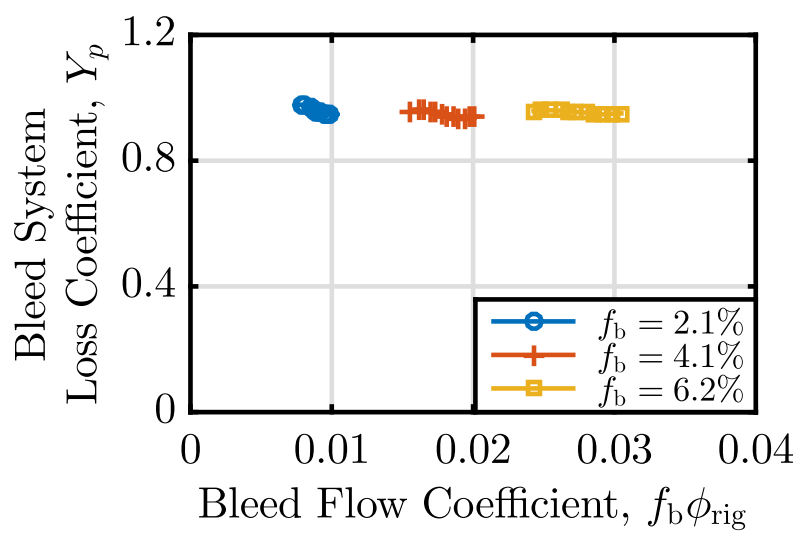

Fig. 8: Measured bleed system loss coefficient characteristics at different bleed rates. The loss coefficient is a weak function of bleed rate and operating point, varying by $\pm 2.2 \%$ over all tested conditions.

Figure 8 shows the measured values of bleed system loss coefficient, Eq. (5), across the compressor operating range, for different bleed rates. The loss coefficient is plotted against the bleed flow coefficient, $f_{\mathrm{b}} \phi_{\text {rig }}$, which scales with the bleed mass flow. Figure 8 is a non-dimensional loss verses mass flow characteristic for the bleed system. For each bleed rate, the loss coefficient is constant across the operating range within \pm 0.015 bleed system inlet dynamic heads, or $\pm 1.7 \%$. It is also constant for the different bleed rates tested, with the average loss coefficient for each bleed rate within \pm 0.007 bleed system inlet dynamic heads, or $\pm 0.7 \%$. The flat loss characteristic, the coefficient varying by $\pm 2.2 \%$ over all tested conditions, implies that, given the stagnation pressure and dynamic head of the flow at inlet to the bleed system, the bleed flow delivery pressure can be predicted for different bleed rates and operating points. The loss coefficient also provides a suitable metric for comparing different bleed system designs. The overall average value of loss coefficient for the bleed rates tested is 0.95 , i.e. most of the dynamic head available at inlet to the control volume is lost. The reason why the loss coefficient takes a constant value is explained, with reference to the loss mechanisms, in the following section.

\section{BLEED SYSTEM LOSS GENERATION}

In this section, the research compressor bleed system flow features, simulated with CFD, are studied to identify loss generation mechanisms. The contribution of each mechanism to total loss is then compared.

Measurements of static pressure in the research compressor show that a separation exists over the front face of the bleed slot. The pressure variation along the slot face, as a function of radial distance, is plotted in Fig. 9, using a static pressure coefficient defined,

$$
C_{p}=\frac{p-p_{0 \mathrm{CVin}}}{\left(p_{0}-p\right)_{\mathrm{CVin}}}
$$

At all bleed rates, there is negligible pressure variation of \pm 0.025 inlet dynamic heads over the measurement locations. This suggests that the flow separates before 10\% radial distance. Also plotted in Fig. 9 are the corresponding data for the research 


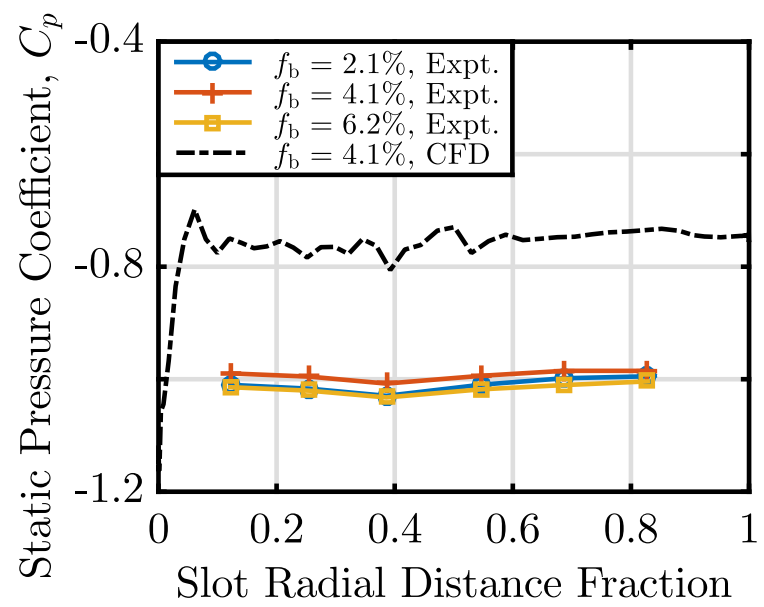

Fig. 9: Measured and computed static pressure distributions in research compressor bleed slot, $\phi_{\text {stg }}=0.43$ There is negligible pressure recovery through the slot in the experiment, less than 5\% bleed system inlet dynamic head, as expected in separated flow.

compressor simulation, which show a flat pressure profile over 95\% of the slot extent. Flow accelerates around the upstream corner of the slot, and then diffuses until 5\% radial distance, where the flow separates. Although there is a difference in the separation location, the measured and computed flow structures are qualitatively similar: both display large separations which dominate the bleed slot flow.

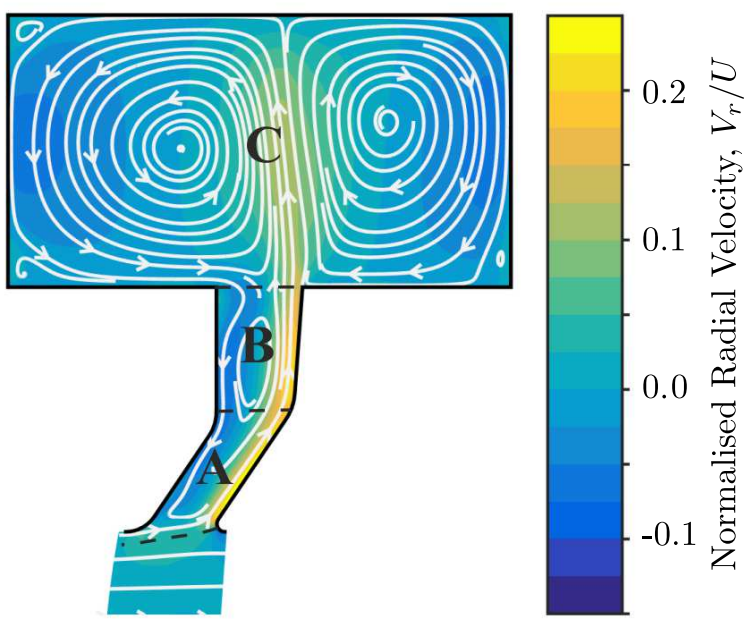

Fig. 10: Predicted contours of normalised radial velocity with streamlines, research compressor, meridional plane at $45^{\circ}$ from off-take duct, $\phi_{\text {stg }}=0.43, f_{\mathrm{b}}=4.1 \%$.

The flow structure in the research compressor bleed system, obtained from CFD, is illustrated in Fig. 10. Contours of radial velocity are shown for a meridional plane between the off-take ducts, with meridional streamlines overlaid. As observed in Fig. 9, the flow separates from the upstream corner of the bleed slot, leading to a region of low-velocity recirculating flow occupying approximately two thirds of the slot width. The blockage due to the separation causes the bleed flow to form a high-velocity jet on the rear face of the slot. This jet exits the slot into the plenum and rolls up into two circumferential vortices. Qualitatively, the flow is similar to that previously reported in the literature $[3,6]$. 


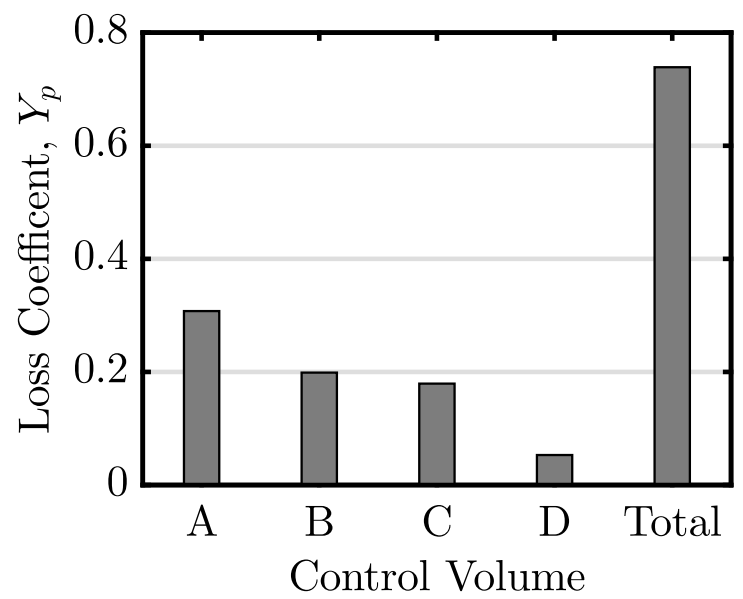

Fig. 11: Predicted sub-volume loss coefficients for research compressor bleed system, $\phi_{\mathrm{stg}}=0.43, f_{\mathrm{b}}=4.1 \%$. Loss coefficient for each sub-volume is defined as the change in stagnation pressure through the sub-volume normalised by the inlet dynamic head at inlet to the overall bleed system control volume. The majority of loss is accounted for in the bleed slot, volumes A and B.

To compare the relative contributions of each of the flow features to the overall loss, the bleed system control volume is divided into four sub-volumes A to D as shown in Fig. 6. Using the CFD flow field, a loss coefficient in the form of Eq. (5) is evaluated for each sub-volume and shown in Fig. 11.

Volume A includes the main annulus flow captured by the bleed system and the lower half of the bleed slot while volume B includes the upper half. Considering volumes A and B together, the loss in the slot accounts for $69 \%$ of the total. The loss in the bleed slot is due to shear at the edges of the jet against both the downstream face of the slot and the low-velocity separated region. The loss in volume A is $54 \%$ greater than that in volume B. This is because the velocity of the jet is greater in the lower half of the slot, as shown by the velocity magnitude contours in Fig. 12, leading to steeper velocity gradients at the jet edges. In volume B, the jet has been decelerated by the walls of the slot and by diffusion due to the increase in area with radius.

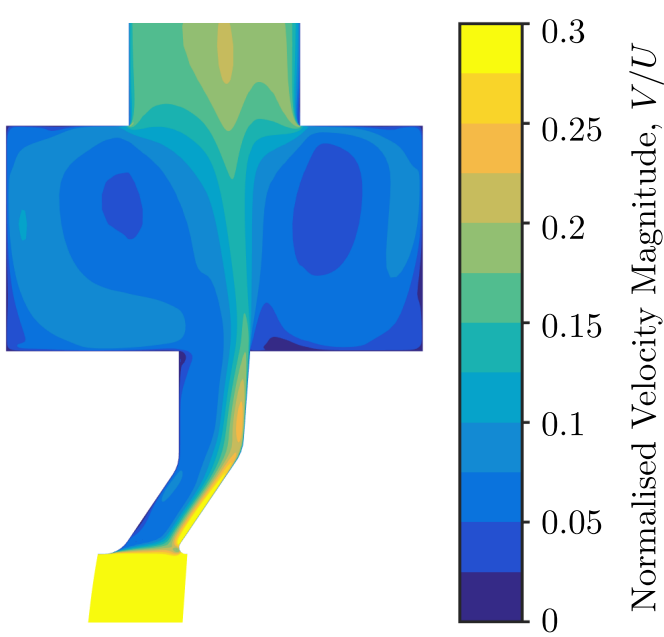

Fig. 12: Predicted contours of normalised velocity magnitude, research compressor, meridional plane at centre of off-take duct, $\phi_{\mathrm{stg}}=0.43, f_{\mathrm{b}}=4.1 \%$. 
In volume $\mathrm{C}$ the bleed flow undergoes a sudden expansion as it leaves the slot and the jet dynamic head is dissipated by mixing with the low-velocity fluid in the plenum chamber. The flow through volume $\mathrm{C}$ contributes $24 \%$ of the total loss. At the inlet to the duct, volume D, the flow separates as shown in Fig. 12. Shear at the boundary of the separation generates loss and volume D contributes $7 \%$ of the total.

Regions of flow where loss is occurring can be directly identified by evaluating the local volumetric entropy generation rate due to irreversibility throughout the flow field, calculated using [10],

$$
\dot{S}_{\mathrm{gen}}=\frac{1}{T} \tau_{i j} \frac{\partial V_{i}}{\partial x_{j}}+\frac{k}{T^{2}}\left(\frac{\partial T}{\partial x_{j}}\right)^{2}
$$

where $\tau_{i j}$ is the viscous shear stress and $k$ is thermal conductivity. The entropy generation rate can then be normalised for the bleed control volume using,

$$
\widetilde{\dot{S}_{\text {gen }}}=\frac{T_{\mathrm{CVin}} \dot{S}_{\text {gen }}}{\rho V_{\mathrm{CVin}}^{3} / L_{x}},
$$

where $T_{\mathrm{CVin}}=p_{\mathrm{CVin}} / \rho R$ and $V_{\mathrm{CVin}}=\sqrt{2\left(p_{0}-p\right)_{\mathrm{CVin}} / \rho}$ are the temperature and velocity at inlet to the bleed system control volume respectively, and $L_{x}$ is the bleed slot inlet width.

Contours of entropy generation rate in the research compressor, in a meridional plane through the off-take duct, are shown in Fig. 13. The highest generation rates occur in regions of high shear: in the casing, slot and duct boundary layers and in the shear layer at the edge of the separation in the bleed slot. The peak entropy generation rate in control volume A is a factor of 5 greater than in volume B and this is consistent with the greater loss coefficient observed in the lower half of the bleed slot. Shear layers at the rear edge of the jet leaving the bleed slot and at the inlet to the off-take duct are also visible in Fig. 13.

In summary, shear within the bleed slot and the sudden expansion at slot exit are the dominant sources of loss which together are responsible for $93 \%$ of the total. Specific loss due to viscous shear scales with velocity squared [11]. Similarly, most of the kinetic energy at the slot exit is lost in the sudden expansion into the plenum, so the specific loss due to this mechanism will also scale with velocity squared. The bleed slot velocity squared itself scales with bleed system control volume inlet dynamic head. Collapse of the static pressure profiles in Fig. 9 shows that the flow structure is unchanged for varying bleed rates. Given a similar flow structure, the area of the bleed slot jet is unchanged and the loss coefficient defined for the bleed system control volume stays constant for varying inlet bleed rate and compressor operating point, as observed in Fig. 8.

The total computed loss coefficient through the bleed system is $0.75,21 \%$ lower than the measured value of 0.95 . This is explained by comparing the measured and simulated flow in the bleed slot. Figure 9 shows that computed $C_{\mathrm{p}}$ increases in the slot inlet up to $5 \%$ radial distance while the measured pressure coefficient remains close to -1 . This means that the simulated flow is attached further around the upstream corner of the slot, the bleed slot separation size is reduced, velocities in the bleed slot jet and expansion into the plenum chamber decrease and the predicted loss is less than that measured. Another way to understand the discrepancy between CFD and experiments is to consider the relationship between $C_{\mathrm{p}}$ at slot exit and $Y_{\mathrm{p}}$. The off-take duct contribution to overall loss is only $7 \%$ so the stagnation pressure in the off-take is approximately equal to the stagnation and static pressures in the plenum chamber. The static pressure in the plenum chamber is also the static 


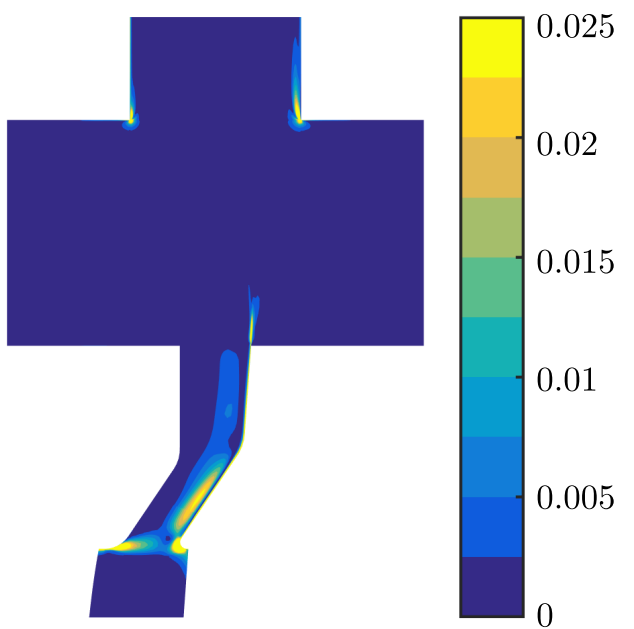

Fig. 13: Predicted contours of normalised entropy generation rate, research compressor, meridional plane at centre of off-take duct, $\phi_{\text {stg }}=0.43, f_{\mathrm{b}}=4.1 \%$.

pressure at exit of the bleed slot so from Equations 5 and $6, Y_{\mathrm{p}} \approx-C_{\mathrm{p}}$. CFD under predicts loss coefficient because it over predicts diffusion in the bleed slot.

Despite the discrepancy between CFD and measurements, the physical loss mechanisms and regions of entropy generation identified above are expected to be representative of the real flow. Given an approximately correct flow structure and the scaling arguments outlined above, relative proportions of total loss are insensitive to separation size. This is because an increase in blockage will increase velocity in the bleed slot, which increases loss in both the bleed slot and plenum chamber due to velocity-squared scaling.

The use of CFD to predict accurate absolute values of loss in the bleed system is an open research question. In particular, the behaviour of large separations, like that in the bleed slot, are sensitive to turbulence modelling. Also, bleed system flow is unlike that in blade passages; the bleed slot geometry has regions of high curvature and the flow is diffusing radially. Even a CFD code with a turbulence model calibrated to predict blade separations accurately will need further refinement for the bleed system flow. Denton [12] suggests that flows with large separations are better modelled with Large Eddy Simulation (LES) calculations than RANS because LES resolves long lengthscale unsteadiness at the edge of the separation. This is an increasingly common approach in blade passages but has not been reported in the open literature for bleed system flows.

CFD simulations in this paper are used to identify physical loss mechanisms and to compare their relative contributions as recommended in the conclusions of [12]. This information was used to inform a successful redesign of the bleed slot geometry for reduced loss, presented in the Design Implications section.

\section{INDUSTRIAL GAS TURBINE COMPRESSOR}

In this section, the loss breakdown and loss mechanisms in the bleed system of an industrial gas turbine high pressure compressor are analysed and compared with the research compressor results.

Figure 14 shows the bleed flow through the bleed system of the industrial gas turbine. CFD-predicted contours of normalised radial velocity are plotted for a meridional plane through an off-take duct with meridional streamlines overlaid. The overall flow structure closely resembles that of the research compressor shown in Fig. 10. 


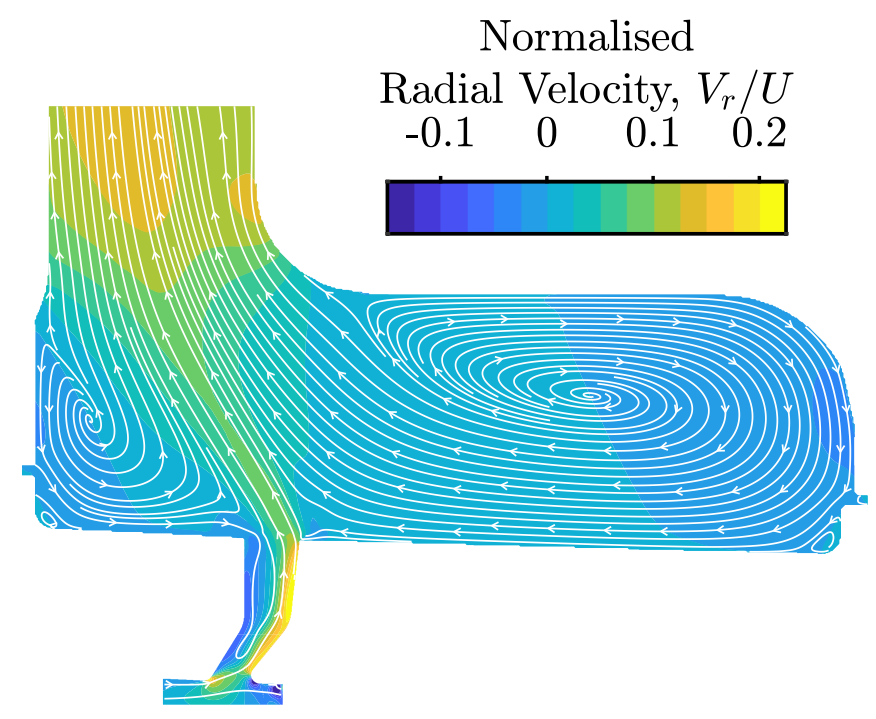

Fig. 14: Predicted contours of normalised radial velocity with streamlines, industrial gas turbine compressor, design operating point, $f_{\mathrm{b}}=3.9 \%$.

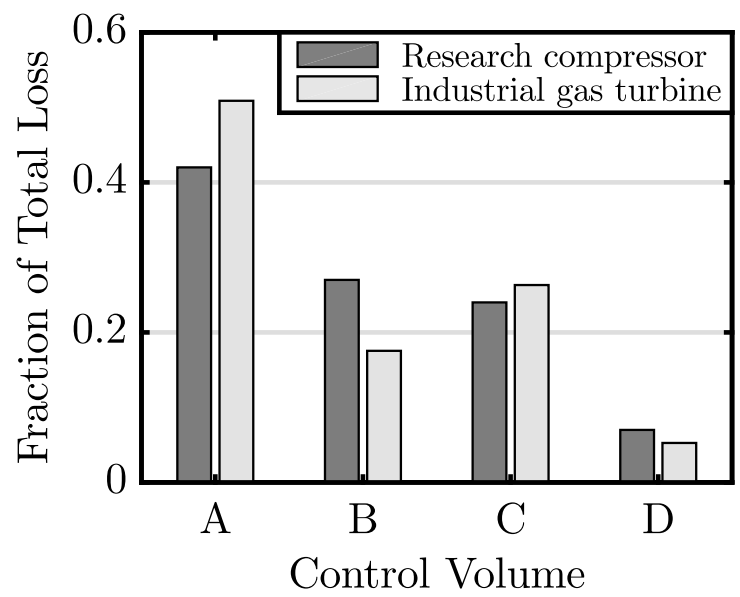

Fig. 15: Predicted fractions of total stagnation pressure loss by sub-volume, for research compressor and industrial gas turbine compressor, design operating points, $f_{\mathrm{b}} \approx 4 \%$.

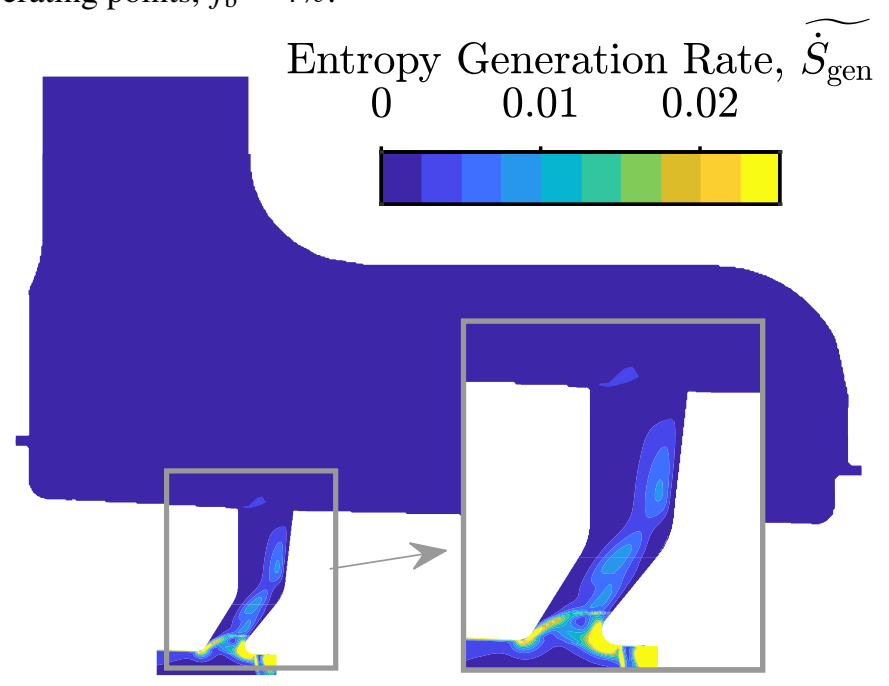

Fig. 16: Predicted contours of normalised entropy generation rate, industrial gas turbine compressor, design operating point, $f_{\mathrm{b}}=3.9 \%$. 
The industrial gas turbine compressor bleed system is divided into the same sub-volumes as shown in Fig. 6, i.e. A: lower half of bleed slot; B: upper half of bleed slot; C: plenum chamber; D: off-take duct. The fraction of total loss in each sub-volume of the research compressor and the industrial gas turbine compressor is compared in Fig. 15. In both cases, the majority of loss occurs in the bleed slot, $69 \%$ for the research compressor and $68 \%$ for the gas turbine compressor. Around a quarter of the loss is accounted for in the plenum chamber of both bleed systems, $23 \%$ for the research compressor and $26 \%$ for the gas turbine compressor. Only a small fraction of loss is attributed to the off-take duct in both cases, $8 \%$ for the research compressor and $6 \%$ for the gas turbine compressor.

Figure 16 shows non-dimensional entropy generation rate for the industrial gas turbine bleed system, calculated using Eqs. (7) and (8). Using temperature and kinetic energy flux at the inlet of the bleed system control volume to nondimensionalise the entropy generation rate allows the research compressor and full scale machine to be compared directly. Comparison of Figs. 16 and 13 show the same regions of high entropy generation: near the corner between the upstream face of the slot and the casing wall where the flow first separates, in the region close to the stagnation point on the corner between the downstream face of the slot and the casing wall, in the boundary layer between the downstream face and the bleed jet, and in the shear layer between the separation and the bleed jet. However, the magnitude of the entropy generation in the first two of these regions is greater in the industrial gas turbine than the research compressor. This is consistent with the ratios of total loss between control volumes A and B, shown in Fig. 15, differ for the two cases.

Overall, the loss breakdowns and loss mechanisms are similar for the two cases. This is because over $90 \%$ of the loss is accounted for by the shear flow in the bleed slot and expansion into the plenum, and these are set by the large, recirculating separation in the bleed slot. Differences in bleed system design between the research compressor and the industrial gas turbine are not significant enough to change this overall flow structure and the associated loss mechanisms. Use of the non-dimensional loss parameters means that low-speed research and full scale industrial gas turbine bleed systems can be compared directly.

\section{DESIGN IMPLICATIONS}

\section{Bleed slot design}

Losses in the bleed system scale with velocity squared. Therefore, the task of a bleed system designer is to diffuse the flow, to both reduce shearing losses within the bleed slot, and reduce the lost dynamic head at slot exit.

For the geometries studied in this paper the majority of loss occurs in the bleed slot. Increasing the upstream inlet radius [2] or inclining the slot towards the axial [3] has been shown to reduce the size of the bleed slot separation. This lowers the velocity of the flow passing along the downstream face of the bleed slot and hence reduces entropy generation. The research compressor bleed slot geometry was redesigned with the aim of reducing the measured loss. The volume envelope of the bleed slot cannot be increased due to mechanical constraints on the compressor rig, so the new geometry is formed using rapid-prototyped inserts fitted to the existing slot as shown in Fig. 17. The redesigned slot geometry has an upstream inlet radius of $1.5 L_{x}$, increased from $0.5 L_{x}$ for the datum design, while the exit area of the slot is reduced by $80 \%$.

The redesigned slot geometry was tested with a bleed rate, $f_{\mathrm{b}}=4.1 \%$; Fig. 18 shows bleed loss coefficient against bleed flow coefficient compared with the datum case. The redesign reduces bleed loss coefficient by 0.29 to 0.33 inlet dynamic 


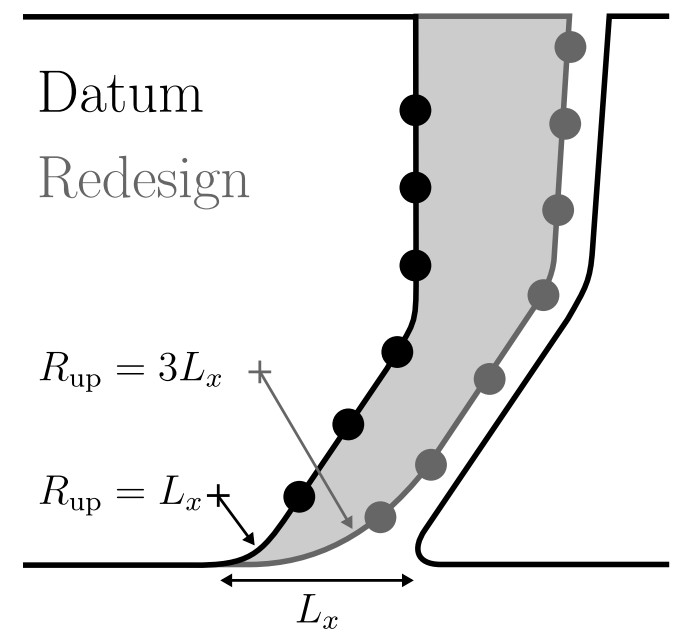

Fig. 17: Datum and redesigned slot geometry with static pressure tapping locations.

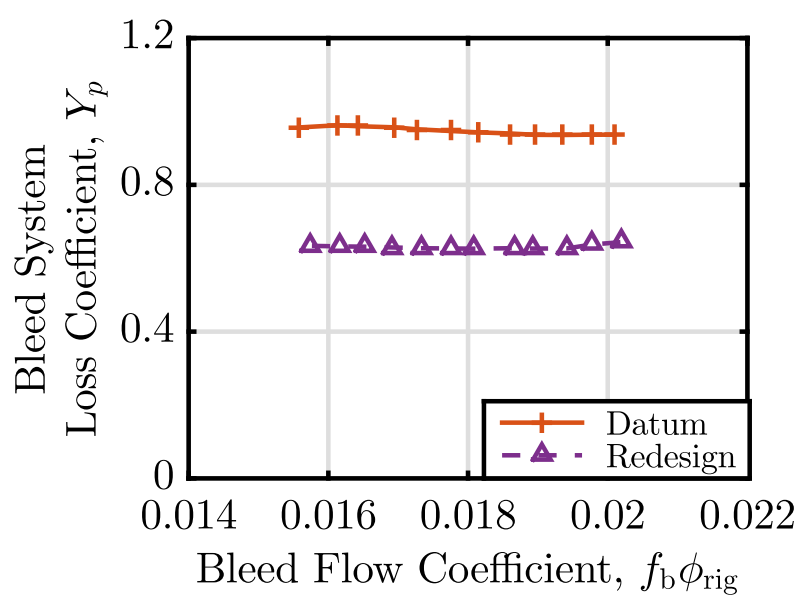

Fig. 18: Measured bleed system loss coefficient characteristics for datum and redesigned geometries at bleed rate $f_{\mathrm{b}}=4.1 \%$.

heads, or 31 to $34 \%$, across the compressor operating range. Figure 19 compares static pressure coefficient on the upstream wall of the slot for the datum and redesigned geometry. At $f_{\mathrm{b}} \phi_{r i g}=0.018\left(f_{\mathrm{b}}=4.1 \%, \phi=0.44\right)$, static pressure increases through the redesigned slot by 0.17 inlet dynamic heads, indicating that the flow remains attached and diffuses through the slot.

In practice, this type of narrow slot may not be possible due to constraints on assembly or the need to pass higher bleed rates for stage matching at start up. A more sophisticated design study could optimise the geometry using CFD, for example by maximising the bleed slot diffusion while maintaining attached capacity for handling bleed. The redesign presented here demonstrates, however, that improvements in bleed system performance can be achieved. For different applications the balance of loss mechanisms may change, e.g., increased off-take duct loss may occur in highly space-constrained aeroengines with small plenum chambers. However, the approach of using the non-dimensional entropy generation rate to identify regions of high loss, and evaluating bleed loss coefficients to compare different designs, can always be applied. 


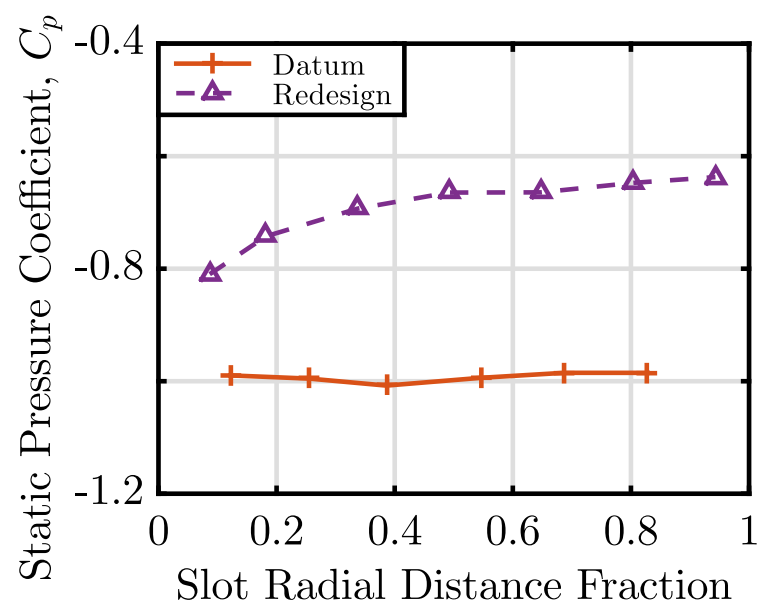

Fig. 19: Measured static pressure distributions in bleed slot for datum and redesigned geometries at $\phi_{\text {stg }}=0.43$ and bleed rate $f_{\mathrm{b}}=4.1 \%$.

\section{Model fidelity and secondary air systems}

Bleed systems feed the secondary air system which is often modelled as a network of pipes and chambers [13]. Stagnation pressure losses in the network are expressed as loss coefficients which are determined from correlations for each element in the system. Bleed flows from the main passage into the secondary air system are represented in the network as inlet boundary conditions with prescribed pressures and temperatures. The location of the interface between the main passage flow and the secondary air system network model can vary; for example, conditions in the off-take duct of the industrial gas turbine modelled in this paper could be passed to an inlet condition for the network model. Downstream effects should be considered when designing individual parts of the system. For example, a bleed slot could be designed which accelerates the flow and results in low levels of loss. However, this would not result in a more efficient bleed system as the additional dynamic head would eventually be lost downstream through diffusion or a sudden expansion.

At early stages in the design process bleed system CFD may not be available. Instead, the bleed system can be considered as a component in the network model with an inlet boundary at CVin, Fig. 6. The results in Fig. 8 suggest this type of bleed system can be approximated using a loss coefficient of one dynamic head. The CVin inlet conditions for the network model are then obtained from a main passage flow radial profile at the bleed location, available from existing CFD simulations (bleed geometry is not required) or rig data.

CFD simulations of the main passage flow including the bleed slot but not the plenum chamber or off-take ducts, are sometimes used for simplicity [14,15]. However, the contours and streamlines in Figs. 10 and 14 show flow recirculating into the slot from the plenum chamber. Imposing an exit mass flow or pressure at this location will result in an unrealistic bleed slot flow constrained by the exit boundary condition. For this reason, single-passage CFD calculations modelling bleed slot flow should also include the plenum chamber geometry. Figures 11 and 15 show that loss associated with the off-take duct is small (7\% in the cases studied here) compared to the bleed slot and plenum chamber. This means that it is an acceptable approximation to replace the discrete off-take duct geometry with an axisymmetric exit boundary condition at the top of the plenum chamber, an approach adopted by Leishman et al. [3]. 


\section{Loss accounting}

A number of researchers have studied the use of bleed air for flow control in compressors. For example, Gbadebo et $a l$. [16] use tailored boundary layer suction with a bleed rate of $0.7 \%$ to reduce loss, increase loading and improve uniformity of exit flow in a stator cascade by reducing the size of corner separations. Walker et al. [8] and Siggeirsson et al. [17] have investigated how bleed can be used to improve the performance of S-shaped compressor ducts by preventing boundary layer separation on highly-loaded endwalls. For this type of flow control to be useful, the overall cycle efficiency has to improve so the bleed flow losses must be included. Evans and Hodson address this issue in their paper 'The Cost of Flow Control' [18]. The bleed air contribution to loss is assessed with a loss coefficient, however, the dynamic head in the denominator is based on average free-stream conditions rather than those at entry to a bleed flow control volume. The bleed loss coefficient introduced in this paper is the appropriate non-dimensional characterisation for loss in the bleed system, and enables different flow control methods to be compared consistently at different compressor operating points and bleed rates. 


\section{CONCLUSIONS}

\section{General Findings}

1. The compressor efficiency defined for a control volume including both mainstream and bleed flow reduces as bleed rate is increased. The stage efficiency characteristics, including only mainstream flow, collapse towards one curve for different bleed rates, showing that the drop in compressor efficiency is due to losses in the bleed system.

2. For bleed systems representative of industrial gas turbines, the dominant loss mechanisms are shear in a high-velocity jet at the rear face of the bleed slot and viscous mixing of this jet with low-velocity fluid in the plenum chamber.

3. The correct non-dimensional parameter for bleed system performance is a loss coefficient for a control volume including only the flow passing through the bleed system. Loss due to the identified mechanisms scales with the control volume inlet dynamic head, so that the loss coefficient is a weak function of compressor operating point and bleed rate.

\section{Specific Findings}

1. The peak research compressor isentropic efficiency drops by $2.0 \%$ points as bleed rate is increased to $6.2 \%$, while the peak stage efficiency varies by less than $\pm 0.2 \%$ points. Loss in the bleed system causes a drop in efficiency an order of magnitude greater than any changes in stage performance.

2. Computations of the research compressor show that with a bleed rate of $4.1 \%, 69 \%$ of total loss occurs in the bleed slot, $24 \%$ in the plenum chamber, and $7 \%$ in the off-take ducts. Taken together, shear in the bleed slot and mixing in the plenum chamber comprise $93 \%$ of total loss.

3. The bleed system loss coefficient for the research compressor takes a value of 0.95 bleed system inlet dynamic heads. The value varies by $\pm 2.2 \%$ across the compressor operating range and bleed rates tested.

4. The breakdown of loss through the bleed system and the loss generation mechanisms are similar for a low-speed research compressor and a full-scale industrial gas turbine compressor with similar bleed system geometries.

\section{Acknowledgments}

The authors are grateful for the support of Mitsubishi Heavy Industries during the course of this project, and, in particular, the assistance of Dr. S. Uchida, Dr. E. Ito, Mr. T. Walker, Mr. R. Mito, and Mr. S. Yamashita. The authors would also like to thank Dr. J. Taylor of the Whittle Laboratory for his help with the creation of the research compressor computational mesh. 


\section{NOMENCLATURE}

\section{Roman}

$f_{\mathrm{b}} \quad$ Bleed rate [-]

c $\quad$ Blade chord [m]

$C_{p} \quad$ Static pressure coefficient [-]

$h \quad$ Specific enthalpy $\left[\mathrm{J} \mathrm{kg}^{-1}\right]$

$L_{x} \quad$ Bleed slot inlet axial width [m]

$\dot{m} \quad$ Mass flow rate $\left[\mathrm{kg} \mathrm{s}^{-1}\right]$

$p \quad$ Pressure $[\mathrm{Pa}]$

$r \quad$ Radial coordinate $[\mathrm{m}]$

$\dot{S}_{\text {gen }} \quad$ Volumetric entropy generation rate $\left[\mathrm{JK}^{-1} \mathrm{~m}^{-3} \mathrm{~s}^{-1}\right]$

$T \quad$ Temperature $[\mathrm{K}]$

$U \quad$ Midspan blade speed $\left[\mathrm{m} \mathrm{s}^{-1}\right]$

$V \quad$ Velocity $\left[\mathrm{m} \mathrm{s}^{-1}\right]$

$\dot{W}_{x} \quad$ Shaft power $\left[\mathrm{J} \mathrm{s}^{-1}\right]$

$x \quad$ Axial coordinate $[\mathrm{m}]$

$Y_{p} \quad$ Bleed system loss coefficient [-]

$k \quad$ Thermal Conductivity $\left[\mathrm{J} \mathrm{K}^{-1} \mathrm{~m}^{-1} \mathrm{~s}^{-1}\right.$ ]

\section{Greek}

$\mu \quad$ Dynamic viscosity $\left[\mathrm{m}^{2} \mathrm{~s}^{-1}\right]$

$\rho$ Density $\left[\mathrm{kg} \mathrm{m}^{-3}\right]$

$\phi \quad$ Flow coefficient [-]

$\psi \quad$ Stage loading coefficient [-]

$\eta \quad$ Isentropic efficiency [-]

$\Delta \eta \quad$ Lost isentropic efficiency [-]

$\tau$ Torque $[\mathrm{Nm}]$

$\tau_{i j} \quad$ Viscous shear stress $\left[\mathrm{Nm}^{-2}\right]$

$\omega \quad$ Blade angular velocity $\left[\mathrm{rad} \mathrm{s}^{-1}\right]$

\section{Subscripts}

$0 \quad$ Stagnation conditions

1 to 5 Mainstream measurement stations (Fig. 3)

b Off-take duct measurement station

CVin Bleed system control volume inlet conditions

rig Rig control volume

stg Stage control volume 


\section{APPENDIX: EXPERIMENTAL CALIBRATION FACTORS}

In this Appendix, the methods used to derive mass flow and mass-averaged stagnation pressure at various stations during the measurement of a compressor characteristic are described.

The rig inlet mass flow can be found by performing a traverse at station 1 and integrating over the flow area. For characteristics, however, it is inconvenient to perform a full traverse at every required operating point. Instead, the traversemeasured mass flow is compared with the inlet dynamic head, as described by Dunkley [19], to form a non-dimensional calibration factor, $K_{m}$, defined,

$$
K_{m}=\iint \frac{\rho V_{x \mathrm{pr}}}{\sqrt{\rho\left(p_{0 \text { in }}-p_{\text {in }}\right)}} \mathrm{d} A,
$$

where $V_{x p r}$ is the axial velocity calculated from traverse measurements, $p_{0 \text { in }}$ and $p_{\text {in }}$ are measured by Pitot tubes and pressure tappings in the inlet section (upstream of the IGVs) and $\rho$ is the inlet density. This calibration is used with the measured inlet dynamic head while recording a characteristic to provide an inlet mass flow according to,

$$
\dot{m}_{1}=K_{m} \sqrt{\rho\left(p_{0 \text { in }}-p_{\text {in }}\right)} .
$$

In a similar way, the mass-averaged value of stagnation pressure at a particular measurement station can be found by performing a traverse and integrating across the flow area. For convenience, calibration factors are derived from traverse data. For example, for station 1, a calibration factor $K_{p 01}$ links stagnation pressure measured by the inlet Pitot tubes and that calculated from traverses,

$$
K_{p 01}=\frac{p_{0 \text { in }}-\overline{p_{0 \mathrm{pr}}}}{p_{0 \text { in }}-p_{\text {in }}},
$$

so that the calibrated rig inlet stagnation pressure $p_{01}$ is,

$$
p_{01}=p_{0 \text { in }}-K_{p 01}\left(p_{0 \text { in }}-p_{\text {in }}\right),
$$

where $\overline{p_{0 p r}}$ is the mass-averaged stagnation pressure calculated from traverses at station 1. Calibration factors of this form are also used to calculate: $p_{03}, p_{0 \mathrm{CVin}}$, and $\left(p_{0}-p\right)_{\mathrm{CVin}}$. For CVin conditions, the calibration factors are found by integrating traverse data down from the casing until the measured bleed mass flow is obtained, not integrating over the whole flow area. This means that the CVin calibration factors are a function of bleed rate, so values are measured separately at bleed rates of $2.1 \%, 4.1 \%$ and $6.2 \%$.

The value of the compressor exit stagnation pressure, $p_{05}$, cannot be found from a calibration factor of the above form because the pressure rise across the compressor varies with operating point. Instead, traverse data at station 5 is used to produce a curve fit for exit flow angle, $\alpha_{5}$, across the compressor operating range. The exit static pressure, $p_{5}$, is measured using tappings, allowing the stagnation pressure to then be found according to,

$$
p_{05}=p_{5}+\frac{1}{2} \rho\left(\frac{\phi_{\text {stg }} U}{\cos \alpha_{5}}\right)^{2} .
$$




\section{References}

[1] Bogard, D. G., and Thole, K. A. 2006. "Gas Turbine Film Cooling." J. Propulsion and Power. 22(2): 249-270

[2] Leishman, B. A., Cumpsty, N. A., and Denton, J. D. 2007. "Effects of Bleed Rate and Endwall Location on the Aerodynamic Behavior of a Circular Hole Bleed Off-Take.” ASME J. Turbomach., 129: 645-658.

[3] Leishman, B. A., Cumpsty, N. A., and Denton, J. D. 2007. "Effects of Inlet Ramp Surfaces on the Aerodynamic Behavior of Bleed Hole and Bleed Slot Off-Take Configurations.” ASME J. Turbomach., 129: 659-668.

[4] Peltier, V., Dullenkopf, K., and Bauer, H. J. 2012. "Experimental Investigation of the Performance of Different Bleed Air System Designs.” ASME Turbo Expo 2012, GT2012-68242

[5] Peltier, V., Dullenkopf, K., and Bauer, H. J. 2014. "Numerical Investigation of the Aerodynamic Behaviour of a Compressor Bleed-Air System.” ASME Turbo Expo 2014, GT2014-25822.

[6] Gomes, R., Schwarz, C. and Peitzner, M., 2005. "Aerodynamic Investigations of a Compressor Bleed Air Configuration Typical for Aeroengines." ISABE-2005-1264.

[7] Walker, A. D., Denman, P. A., and McGuirk, J. J., 2004. "Experimental and Computational Study of Hybrid Diffusers for Gas Turbine Combustors.” ASME J. Eng. Gas Turbines Power, October 2004, 126(4): 717- 725.

[8] Walker, A. D., Barker, A. G., and Carrotte, J. F. 2011. "Numerical Design and Experimental Evaluation of an Aggressive S-shaped Compressor Transition Duct with Bleed.” ASME Turbo Expo 2011, GT2011-45628.

[9] Brandvik, T., and Pullan, G. 2011. "An Accelerated 3D Navier-Stokes Solver for Flows in Turbomachines." ASME J. Turbomach., 133(2): 021025.

[10] Greitzer, E. M., Tan, C. S., and Graf, M. B. 2007. "Internal Flow: Concepts and Applications.” Cambridge University Press"

[11] Denton, J. D. 1993. “Loss Mechanisms in Turbomachines.” 1993 IGTI Scholar Lecture, ASME Paper No. 93-GT4351993.

[12] Denton, J. D., 2010 “Some Limitations of Turbomachinery CFD.” ASME Turbo Expo 2010, GT2010-22540

[13] Kutz, K. J., and Speer, T. M., 1994. "Simulation of the Secondary Air System of Aero Engines." ASME J. Turbomach., April 1994, 116(2): 306-315.

[14] Wellborn, S. R., and Koiro, M. 2002. "Bleed Flow Interactions with an Axial Flow Compressor Powerstream." AIAA/ASME Joint Propulsion Conference, AIAA 2002-4057.

[15] Elmendorf, W., Mildner, F., Röper, R., Krüger, U., and Kluck, M. 1998. “Three-Dimensional Analysis of a Multistage Compressor Flow Field.” ASME Turbo Expo 1998, 98-GT-249.

[16] Gbadebo, S. A., Cumpsty, N. A., and Hynes, T. P. 2008. "Control of Three-Dimensional Separations in Axial Compressors by Tailored Boundary Layer Suction.” ASME. J. Turbomach., January 2008, 130(1):011004.

[17] Siggeirsson, E. M., Andersson, N., and Wallin, F. 2018. "Numerical and Experimental Study on Bleed Impact on Intermediate Compressor Duct Performance” ASME Turbo Expo 2018, GT2018-76649.

[18] Evans, S. W., and Hodson, H. P. 2011. "The Cost of Flow Control in a Compressor" ASME Turbo Expo 2011, GT2011-45059.

[19] Dunkley, M. J. 1998. "The Aerodynamics of Intermediate Pressure Turbines.” PhD Thesis, University of Cambridge. 